\title{
Optimizing The Functional Performance of Road Network using Vulnerability Assessment to Cope with Unforeseen Road Incidents
}

\author{
Mukhammad Rizka Fahmi Amrozi ${ }^{1, *}$, Raihan Pasha Isheka ${ }^{2}$ \\ ${ }^{1}$ Department of Civil and Environmental Engineering, Universitas Gadjah Mada, Yogyakarta, INDONESIA \\ Jalan Grafika No 2 Yogyakarta \\ ${ }^{2}$ Department of Civil Engineering, Vocational College, Universitas Gadjah Mada, Yogyakarta, INDONESIA \\ Jalan Yacandra Unit IV Yogyakarta \\ *Corresponding authors: fahmi.amrozi@ugm.ac.id
}

SUBMITTED 09 August 2021 REVISED 09 September 2021 ACCEPTED 02 October 2021

\begin{abstract}
An Urban Road network is often used for multipurpose trips, due to their transportation functions, such as attractiveness and orientation, as well as social, ecological, and economic features. In Indonesia, road incidents have reportedly increased during the last decade because of a higher frequency of natural hazards, accidents, and on-street mass demonstrations. These incidents are found to degrade or terminate road access, forcing users to utilize alternative routes and decreasing the service performance in adjacent directions. Due to the unexpected occurrences at any location and time, there is a need to investigate the impact of random incidents on road performances. Several accessibility indexes have also been used to evaluate the vulnerability of road networks. However, this is less practical in Indonesia, with the road authority using functional performances as the indicator. This indicates the need for an index to be developed based on road performance parameters. Therefore, this study aims to develop a road performance-based vulnerability index known as the RCI (Road Criticality Index). Combined with a traffic simulation tool, this system is used as an alternative index to assess vulnerabilities, by identifying the road(s) providing worse consequences due to unforeseen incidents. This simulation was conducted by using the PTV Visum, assuming a road section is closed due to the worst incident scenarios. The result showed that the RCI offered a more comprehensive assessment than the existing indicator (volume capacity ratio). The RCI included travel speed and mobility components for evaluating both local and global road performances. With the knowledge of the most vulnerable locations and their consequences, road authorities can prioritize maintenance and development strategies based on the criticality index. Also, preventive measures should be conducted to mitigate risk under a constrained budget. This methodology can be applied to sustainably enhance the resilience of urban road networks.
\end{abstract}

KEYWORDS Urban Road; Vulnerability Index; Road Performance; PTV Visum; Road Network Resilience.

(c) The Author(s) 2022. This article is distributed under a Creative Commons Attribution-ShareAlike 4.0 International license.

\section{INTRODUCTION}

\subsection{Background}

Most Indonesian areas located on the pacific ring of fire and at the meeting point of three continental plates are prone to natural disasters, such as earthquakes and volcanic activities (Stanton-Geddes and Vun, 2019). According to The World Bank (2019), Yogyakarta as one of the most prone metropolitan cities in Indonesia, was categorized vulnerable to unforeseen road incidents and major natural disasters, such as strong winds, landslides, earthquakes, tsunami, and volcanic activity. As an educational city where several prestigious public and private universities are established, the road sections/junctions in Yogyakarta are often

disrupted due to mass demonstration activities, which are essentially legal to convey aspirations based on human rights and law protection. These are often carried out by marching through several streets and staying at a specific location like Malioboro road and KM-0 intersection (Mahpudin et al., 2020). According to BPS statistics (2021), road disruptions increased by $1-3 \%$ due to a higher frequency of natural hazards, traffic accidents, and on-street mass demonstrations during previous decades. This raised public awareness regarding the consequences of these incidents on the road networks' performance reliability. 
Transport networks should be managed to achieve a reliable and optimum level of performance to all locations in need of commutation service (Amrozi and Evdorides, 2019). Depending on the type of threat, road incidents are found to degrade or terminate transport access, as well as worsen service performance on the adjacent networks. Since these incidents are bound to unexpectedly occur at any location and time, the need to investigate the impact of any random road occurrences on network performance is very essential, through vulnerability assessment. This is important due to the massive impact of the disturbance on the critical $\operatorname{road}(\mathrm{s})$, which triggers a systemic chain effect on the overall network performances, including socio-economic activity losses. Several accessibility indexes have reportedly been used to assess the vulnerability of road networks (Sugishita and Asakura, 2021). However, this is less practical in Indonesia, as the road authority used functional performance as the standard indicator. Also, most of them are found to only use a single indicator, such as travel time, cost, distance, and link volume. Therefore, a new performance-based vulnerability index should be developed based on some road performance parameters, to measure the impact and identify the most susceptible network section(s). Road managers should also prioritize performances based on the criticality index value, and adopt preventive measures to mitigate exposure risks under a constrained budget.

\subsection{Vulnerability Assessment}

Vulnerability is defined as the susceptibility to any incidents capable of reducing road network performances (Berdica, 2002). This concept emphasizes the consequences of several incomplete components (links or nodes), regardless of the possibility of the failure (Taylor and Susilawati, 2012), indicating that network susceptibility focuses on the weaknesses and shortcomings for connectivity. Furthermore, this provides a more sensitive analysis of road network impact performance when there is a disruption at a specific link. The high vulnerability index states that the occurrence of disruptions at any component(s) leads to a massive negative impact on all road networks. At the planning stage, vulnerability analysis is used as guidance for generating a new road alignment and standard, utilized as an alternative route. Meanwhile, this evaluation is used to identify the most vulnerable road during the operation stage. Depending on the threat, different actions were adopted to swiftly minimize impact and restore road performances.

Vulnerability is generally assessed using several methods, including inventory-based risk assessment, as well as topological, serviceability, and accessibility methods (Taylor, 2017). According to Jenelius and Mattsson (2015), the concept and measurement of vulnerability focused on the potential degradation of road networks and their impacts on society. Although serviceability and accessibility methods are often used for the measurement of network vulnerabilities, they still offered better clarity as performance standards. The incident types reducing serviceability often include vehicle crashes, roadworks, traffic congestions, on-street and weather events, as well as natural hazards, which are known to cause partial or complete blockages (Taylor, 2017).

Vulnerability methods are known to consider the exposure level of negative impacts, based on the performance measurement changes for a different road network state, such as with and without degraded scenarios. According to the study of Oliveira et al. (2016), the identification of critical links was an outcome of vulnerability assessment. A ranking system for these links is often carried out based on the degree of a negative network impact. Moreover, the traditional practices of road infrastructure management still use volume capacity ratio (VCR) to measure vulnerability, due to being simple and easy to carry out (El-Rashidy and Grant-Muller, 2014). As alternatives, several methods used to measure vulnerability includes (i) Link Importance Index (Rupi et al., 2015), (ii) Network Robustness Index (Scott et al., 2006), (iii) Network Trip Robustness Index (Sullivan et al., 2010), (iv) NQ Index (Nagurney and Qiang, 2008), and (v) 
Network Vulnerability Index (Balijepalli and Oppong, 2014). However, these indices are previously developed to serve a specific purpose and consideration. For example, NTRI emphasizes travel demand variable while LII focuses on link volume and travel cost. Although these models function when appropriately used, they are still likely to lead to bias interpretation when the usage constraint/limitation is violated. Therefore, the selection of these models to assess vulnerability should consider the definition, purpose, scope, and limitation of the index.

\subsection{Functional Performance of Road Network}

Road networks are a fundamental asset to support socio-economic activities, due to being expected to offer convenient, safe, and efficient transportation services to communities (Karlaftis and Kepaptsoglou, 2012). Also, the performance measurement is theoretically a systematic process to ensure the road achieves predetermined goals. According to the OECD (2001), the indicator performance varied depending on the perspectives of the stakeholders. For instance, road users demand top-level performances to minimize cost (RUC). However, road administration aims to optimize total benefit by balancing RUC and RAC (road agency cost) in achieving optimum rewards. Each country is found to probably have different standards and policies in measuring road performance, although most of them still rely on the level of service (LOS) measure developed by The American Association of State Highway and Transportation Officials (AASHTO). This is primarily based on volume capacity ratio (VCR) (Scott et al., 2006), which is argued to likely be insufficient towards assessing the overall traffic condition and performance. In addition, some variables are considered and added to the VCR, towards measuring road performances, e.g. travel time, speed, delay, congestion index, VKT (vehicle-kilometre of travel), PKT (personkilometre of travel), system reliability, and GTC (generalized travel cost) (Taylor, 2017).

\section{METHODS}

Road incidents and natural disasters are events that often occur unexpectedly. The impact of these events is mostly tough to estimate, as the type, exposure, time, and location of their occurrences are still unknown (Auerbach et al., 2016). These conditions are then assessed using a worst-case scenario, assuming that access on a specific road is terminated due to the occurrence of an incident (Susilawati and Taylor, 2008). Therefore, the worst impact of an incident(s) at a road section is modeled as a link closure. Using the PTV Visum software, the impact of this closure within the road network was simulated and compared to normal conditions. This indicated that worse changes led to more critical links in the overall road network performance.

The aim of this study is based on the development of a performance-based vulnerability index, which is to be used as an indicator with the analysis of a traffic simulation tool. This is to compare and assess the degree of road closure impact on the overall network performance, due to the occurrence of incidents. The index value was also compared to normal conditions (without incident) and all possible link scenarios. Subsequently, the overall procedures are shown in Figure 1.

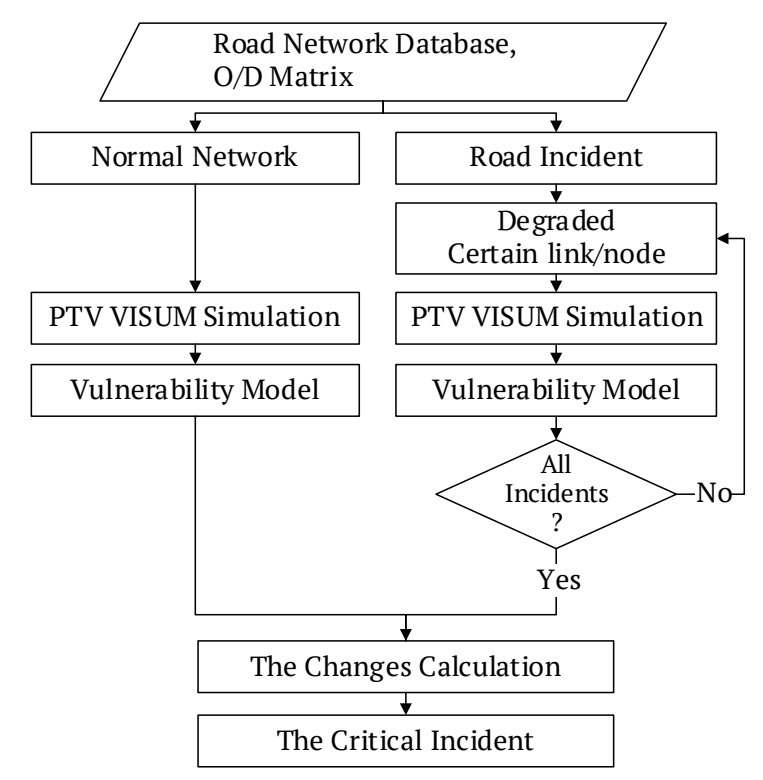

Figure 1. Research methodology flowchart. 


\subsection{Development of Road Network Model}

The location of this study is the urban area of Yogyakarta, an agglomeration region covering the regency of Sleman, Bantul, and Yogyakarta City. This area was selected due to being one of the most vulnerable metropolitan cities in Indonesia (Chapter 1.1.). Also, the selection was based on the identification of the urban road network boundaries, such as the area within the ring road. According to Fitrada et al. (2019), the Yogyakarta road models were developed based on the PTV Visum design of the Special Region of Yogyakarta network. Based on the administrative boundaries of 17 sub-district zones in the urban region of Yogyakarta, the locations for the O/D matrix were formed. To represent the location of a road incident, 89 sections (165 links) were modeled in the PTV Visum, including three types of network function, including primary arterial, as well as secondary artery and collector roads, as shown in Figure 2.

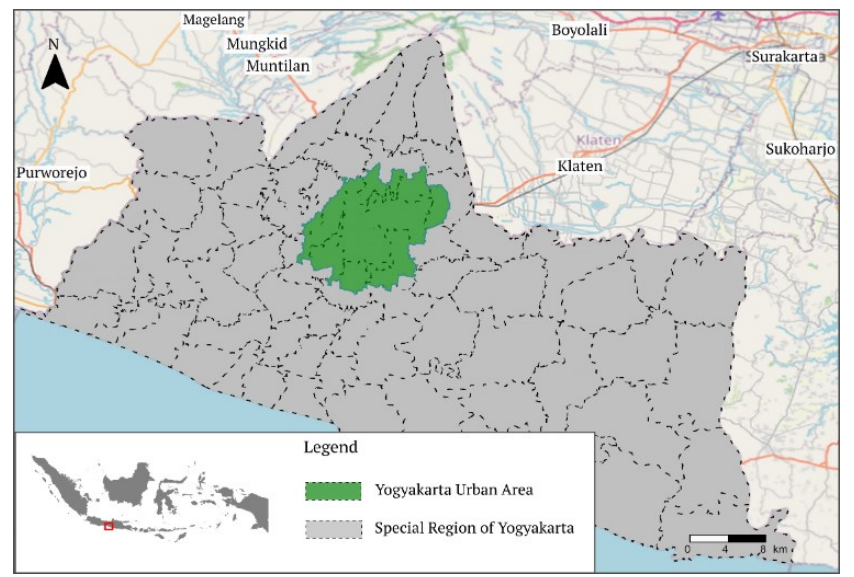

a)

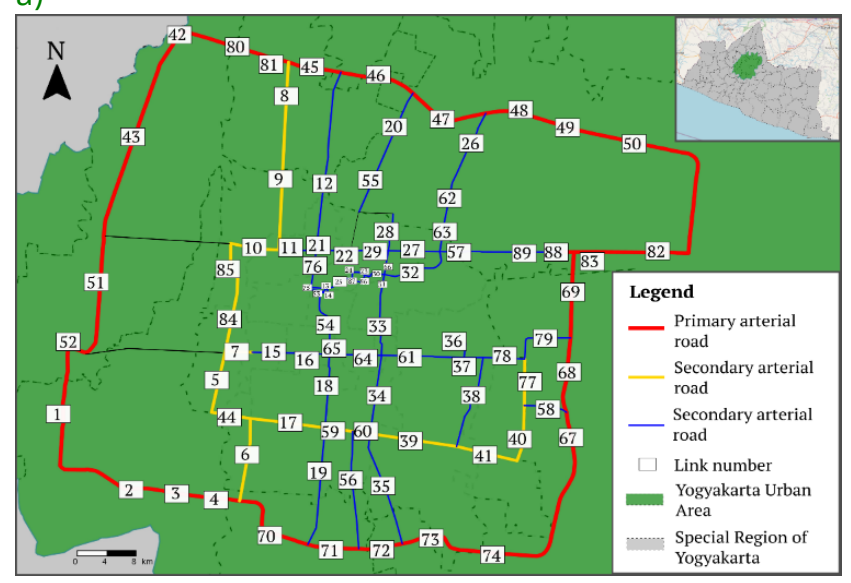

b)

Figure 2. Road network modeled in PTV Visum: a) Location of case study, b) Road sections modeled as links.

\subsection{Traffic Simulation using PTV Visum}

The traffic modeling in this study was simulated using the PTV Visu, based on travel demand (O/D matrix) and networks during a peak hour period in 2019. In the traffic assignment process, the equilibrium method was applied to represent the urban network characteristics. This assignment assumed that travelers were familiar with the Yogyakarta road network or use a guidance tool, such as google maps, to locate the best route with minimum travel time (PTV, 2021). Moreover, the validation value ( $\mathrm{R}$-squared) between the realistic traffic flow base model and average speed was 0.91 each, respectively. This indicated that the base model represented the actual condition. For the incident scenario, a road link was sequentially deleted in each simulation process, with the running procedure being carried out 89 times. Also, the outputs from this modeling procedure were the volume capacity ratio, travel speed, $V K T$, and VHT (vehicle hours travel).

\subsection{Development of Vulnerability Index}

The vulnerability index in this study was developed based on multi-parameters, where the selected components were aggregated into a single composite model, through the referral of a theoretical framework. Also, the development procedure of this index adopted the methodology from Nardo et al. (2008), as shown in Figure 3.

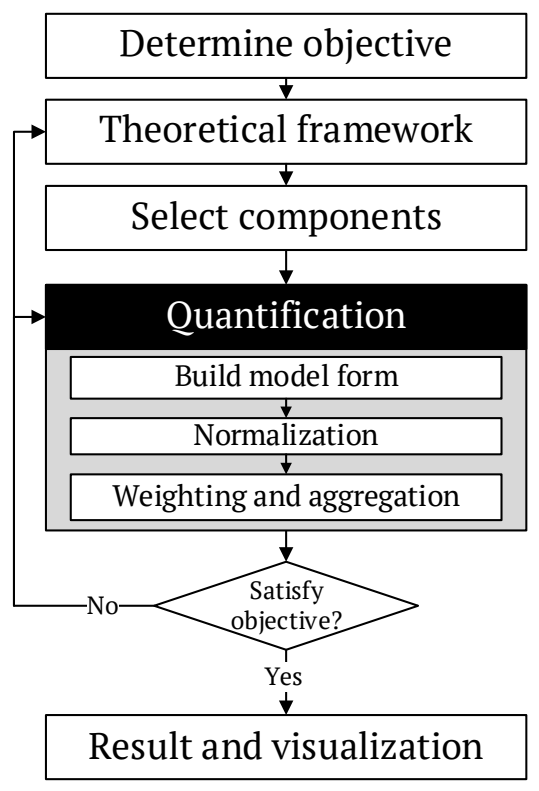

Figure 3. Development of vulnerability model. 


\subsubsection{Components of the vulnerability index}

The functional performances of Indonesian roads are often measured based on the volume capacity ratio and travel speed, known as the level of service (LoS) (Tamin, 2000). This LoS value represents the DOF (degree of freedom) of vehicle movement, which ranges from level $\mathrm{A}-\mathrm{F}$ as the best to worst services, respectively. However, there was no quantitative threshold stated in the latest standard (PM 96/2015) for assessing volume capacity ratio, due to being in KM $14 / 2006$. This indicated that the ratio referred to other associated standards, such as the IHCM (1997), where a road section was categorized as having good performance when $V C R \leqslant 0.75$ (Table $1)$.

Based on speed parameters, the Ministry of Transport (2015) proposed a very high threshold that was hard to achieve. For example, a $70 \mathrm{~km} / \mathrm{h}$ regulation of an average velocity as the minimum performance standard on primary arterial roads. However, setting up 50 and $60 \mathrm{~km} / \mathrm{h}$ for local and secondary arterial/collector roads was impractical for urban networks, due to violating the limit standard. This was in line with Sudibyo et al. (2017), which demonstrated that meeting the PM 96/2015 standards (minimum LoS B or C) was very hard in Indonesia, as most roads were rated LoS $\mathrm{E}$ or worse. Despite the argument, an alternative threshold was still developed based on the expected operational speed from the study of BSN (2004), regarding the provision of a more reasonable value (Table 1). Meanwhile, the threshold for a secondary urban road should be adjusted to $75 \%$, due to often having a lower speed limit and higher disruption, such as onstreet parking and other obstacles.

According to the road section parameters, mobility (network parameter output from PTV Visum) was added to assess the overall impact on the network as a system (global parameter). This is defined as the movement of people or goods, often measured by trips, distance, and speed (Litman, 2016). There is often an assumption that a travel mileage increase benefits society, due to improving the choice and number of destinations attained by people. However, the travel demand in this study was predetermined using a fixed O/D matrix. Furthermore, the number and pattern of trips should be similar for the scenario, with and without the occurrence of incidents. This indicated that an increase in travel mileage signified a delay in reaching a destination worsening road performances. However, there was recently no minimum standard on the existence of mobility in Indonesia. Based on the most critical incidents, the identification process focused on the mobility value changes with and without incidents, to assess the degree of impact. Therefore, the overall vulnerability measurement in this study used four parameters, namely volume capacity ratio, travel speed, $V H T$, and $V K T$, which represented the local and global indicators of road performance. Since these parameters are also available as PTV Visum simulation outputs, their utilization was theoretically approved and practically.

Table 1. Performance standard in Indonesia based on road function

\begin{tabular}{|c|c|c|c|c|c|c|c|c|c|}
\hline \multirow{3}{*}{\multicolumn{2}{|c|}{ Road function }} & \multirow{4}{*}{$\begin{array}{l}\text { Expected } \\
\text { operational } \\
\text { speed } \\
(\mathrm{km} / \mathrm{h})^{*}\end{array}$} & \multicolumn{5}{|c|}{ Good road performance service standard $* *$} & \multirow{2}{*}{\multicolumn{2}{|c|}{$\begin{array}{l}\text { Preferred bad } \\
\text { threshold } * * * *\end{array}$}} \\
\hline & & & \multicolumn{2}{|c|}{ Maximum $V C R$} & \multicolumn{3}{|c|}{ Minimum operational speed $(\mathrm{km} / \mathrm{h})$} & & \\
\hline & & & IHCM/ & KM & KM & PM & BSN/ & Volume & Speed \\
\hline \multirow{3}{*}{ Arterial } & & & & & & & & & \\
\hline & Primary & $50-100$ & 0.75 & 0.45 (LoS B) & 80 (LoS B) & $70(\operatorname{LoS} B)$ & 50 & $>0.75$ & $<50$ \\
\hline & Secondary & $50-80$ & 0.75 & $0.80(\operatorname{LoS} \mathrm{C})$ & $30(\operatorname{LoS} C)$ & $60(\operatorname{LoS} C)$ & 50 & $>0.75$ & $<40$ \\
\hline \multirow[t]{2}{*}{ Collector } & Primary & $40-80$ & 0.75 & $0.50(\operatorname{LoS} B)$ & $90(\operatorname{LoS} B)$ & $70(\operatorname{LoS} B)$ & 40 & $>0.75$ & $<30$ \\
\hline & Secondary & $30-50$ & 0.75 & $0.80(\operatorname{LoS} C)$ & $30(\operatorname{LoS} C)$ & $60(\operatorname{LoS} C)$ & 30 & $>0.75$ & $<25$ \\
\hline Local & Secondary & $30-50$ & 0.75 & $0.85(\operatorname{LoS} \mathrm{D})$ & 15 (LoS D) & $50(\operatorname{LoS} D)$ & 30 & $>0.75$ & $<15$ \\
\hline
\end{tabular}

* based on BSN (2004); VCR=volume capacity ratio; LoS= Level of Service;

** Based on IHCM (1997), BSN (2004), Ministry of Transport (2006), and Ministry of Transport (2015).

**** threshold for bad road performance used to measure vulnerability index. 


\subsubsection{Quantification of the vulnerability index}

Based on this study, the vulnerability parameters were measured based on the results obtained from the PTV Visum simulation. This indicated that the unit of analysis for the indexes was in line with the analytical features of the simulation software, i.e., road section by direction. For instance, a one and two-way network count as one and two analytical units. The general equations to quantify the vulnerability indexes are described in Equation (1) and (2).

$R C I=f(V C R, v, V H T, V K T)$

$R C I=V C R+v+V H T+V K T$

Where $R C I$ is the road criticality index, $V C R$ is the volume capacity ratio, $v$ is the travel speed $(\mathrm{km} / \mathrm{h}), V H T$ is the vehicle hour travel (vehicle hour), and VKT is the vehicle kilometre travel (vehicle $\mathrm{km}$ ). To investigate the practical use of the vulnerability measurement, the index was developed and tested using four different quantification techniques, i.e., M1, M2, M3, and M4.

a) Model 1 (M1) was measured based on the percentage changes in each parameter, due to the scenario of incidents. Afterwards, the change values were sorted. For each parameter, the top five worst changes were provided with 1 point. This was due to the model having four parameters, with scores ranging from $0-4$

b) Model 2 (M2) applied thresholds to count the number of bad performance links, due to the road incidents (Table 1). With a value exceeding the threshold, the direction of the link was counted and categorized as having a bad performance. Afterwards, the increased number of bad links were orderly sorted, as the top five worst changes for each incident were provided with 1 point. Similar to M1, the vulnerability score ranged from 0 to 4 .

c) Model 3 (M3) calculated the percentage changes of each parameter as observed in M1.
However, the results were normalized and not sorted as top five, i.e., divided by its maximum value for each term. Similar to M1 and M2, the score ranged from 0-1 and 0-4 for each component and total marks. However, M3 provided a decimal value to offer more detail and sensitive measurements.

d) Model 4 (M4) is a hybrid approach between M2 and M3, which applied a threshold for each unit of analysis.

\section{RESULTS}

\subsection{Changes in Road Performance}

More than half of the roads $(51.5 \%)$ in the Yogyakarta urban area were in severe congestion $(V C R>0.75)$ during peak hours, based on the normal conditions without incident. With the incident scenarios, the simulation showed that the road performance was worsened at approximately $58.2 \%$, as shown in Figure 4 . This indicated that the impact of incidents on vulnerability parameters was in line with the model assumption, except for mobility values (Table 2). Moreover, the results consistently provided a higher VCR and lower travel speed when a particular road was disrupted. However, the VKT and VHT (Vehicle Kilometre Travel and Vehicle Hour Travel) values were inconsistent due to having a positive or negative outcome, depending on the road closure scenario. For example, road users that often use the northern ring network (Purworejo-Surakarta route) were forced to use alternative routes through the city centre, because of the closure scenario shown in Figure 4. Although this route offered a shorter distance, the travel time was still longer. Meanwhile, the southern ring distance was farther than the inner-city route and relatively delivered a faster trip. Each area also had a different configuration, indicating the variation of an incident impact based on the density and geometric patterns of the network. This was found to provide a reliable alternative route option. 
Table 2. The impact of road incidents on the road network performance in Yogyakarta (the Year 2019)

\begin{tabular}{|c|c|c|c|c|c|c|c|c|c|c|c|c|c|}
\hline \multirow{4}{*}{$\begin{array}{l}\text { Incident } \\
\text { location } \\
\text { (link } \\
\text { number) }\end{array}$} & \multirow{4}{*}{$\begin{array}{l}\text { Road } \\
\text { Function }\end{array}$} & \multicolumn{8}{|c|}{ Changes in road section parameter (local) } & \multirow{2}{*}{\multicolumn{4}{|c|}{$\begin{array}{l}\text { Changes in network parameter (global } \\
\text { Mobility (M1, M2, M3, M4) }\end{array}$}} \\
\hline & & \multicolumn{4}{|c|}{ By raw value (M1 \&M3) } & \multicolumn{4}{|c|}{ By threshold (M2\&M4) } & & & & \\
\hline & & \multicolumn{2}{|c|}{ VCR } & \multicolumn{2}{|c|}{ Travel speed } & \multicolumn{2}{|c|}{ VCR } & \multicolumn{2}{|c|}{ Travel speed } & \multicolumn{2}{|c|}{ VHT } & \multicolumn{2}{|c|}{ VKT } \\
\hline & & $(V C R)$ & $(\%)$ & $(\mathrm{km} / \mathrm{h})$ & $(\%)$ & $(V C R)$ & $(\%)$ & $(\mathrm{km} / \mathrm{h})$ & $(\%)$ & (Veh hour) & $(\%)$ & (Veh km) & $(\%)$ \\
\hline 1 & $\mathrm{AP}$ & 47.2 & 36.5 & $-1,018$ & -18.8 & 39.0 & 49.4 & 28 & 30.8 & $3,141.3$ & 12.8 & $-12,209.8$ & -2.0 \\
\hline 2 & $\mathrm{AP}$ & 37.7 & 29.1 & $-1,005$ & -18.6 & 32.0 & 40.0 & 23 & 25.3 & 240.7 & 1.0 & $-22,538.2$ & -3.7 \\
\hline$\vdots$ & $\vdots$ & $\vdots$ & $\vdots$ & $\vdots$ & $\vdots$ & $\vdots$ & $\vdots$ & $\vdots$ & $\vdots$ & $\vdots$ & $\vdots$ & $\vdots$ & $\vdots$ \\
\hline 47 & $\mathrm{AP}$ & 51.6 & 40.1 & $-1,269$ & -23.4 & 46.0 & 58.2 & 38 & 42. & $5,323.1$ & 21.6 & 28,1 & 4.7 \\
\hline 48 & $\mathrm{AP}$ & 43.8 & 33.8 & & -20.7 & 40.0 & 50.0 & 33 & 36.3 & & 12.8 & 504.2 & 1.4 \\
\hline$\vdots$ & $\vdots$ & $\vdots$ & $\vdots$ & $\vdots$ & $\vdots$ & $\vdots$ & $\vdots$ & $\vdots$ & $\vdots$ & $\vdots$ & $\vdots$ & $\vdots$ & $\vdots$ \\
\hline 87(1way) & KS & 35.0 & 27.0 & $-1,024$ & -18.6 & 33.0 & 41.8 & 25 & & 164.0 & 0.7 & & 0.2 \\
\hline 88 & $\mathrm{AP}$ & 36.8 & 28.5 & $-1,056$ & -19.4 & 33.0 & 42.3 & 31 & 34.8 & 1,261 & 5.1 & $13,243.5$ & 2.2 \\
\hline 89 & KS & 37.4 & 29.0 & $-1,063$ & -19.5 & 33.0 & 42.3 & 28 & 31.5 & $1,070.6$ & 4.3 & $7,856.1$ & 1.3 \\
\hline Min & & 33.3 & 25.6 & $-1,269$ & $-23.4^{*}$ & 27.0 & 33.8 & 19 & 21.1 & -113.2 & -0.5 & $-30,289.9$ & -3.7 \\
\hline $\max$ & & 51.6 & $40.1^{*}$ & -937 & -17.4 & 46.0 & $58.2 *$ & 38 & $42.2^{*}$ & $5,430.3$ & $22.0^{*}$ & $28,104.7$ & $4.7^{*}$ \\
\hline
\end{tabular}

* Max value (used for normalization procedure in M2 and M4); AP= primary artery, AS= secondary artery, KS= secondary collector.

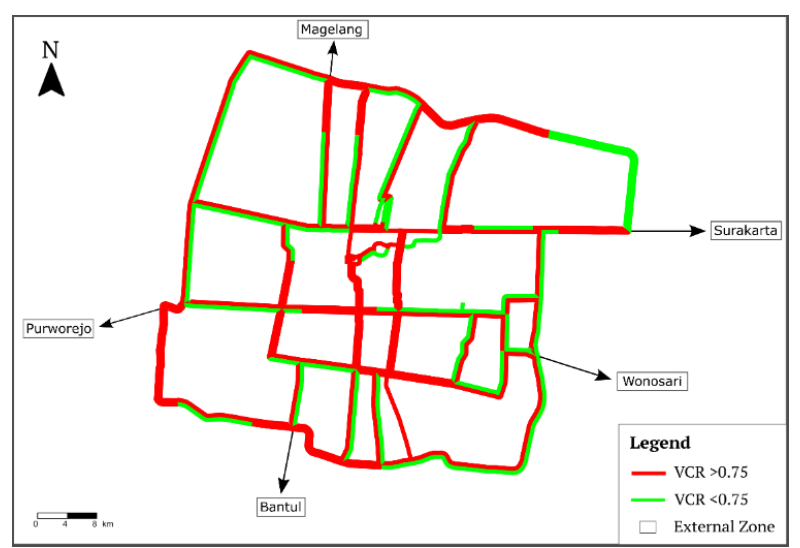

a)

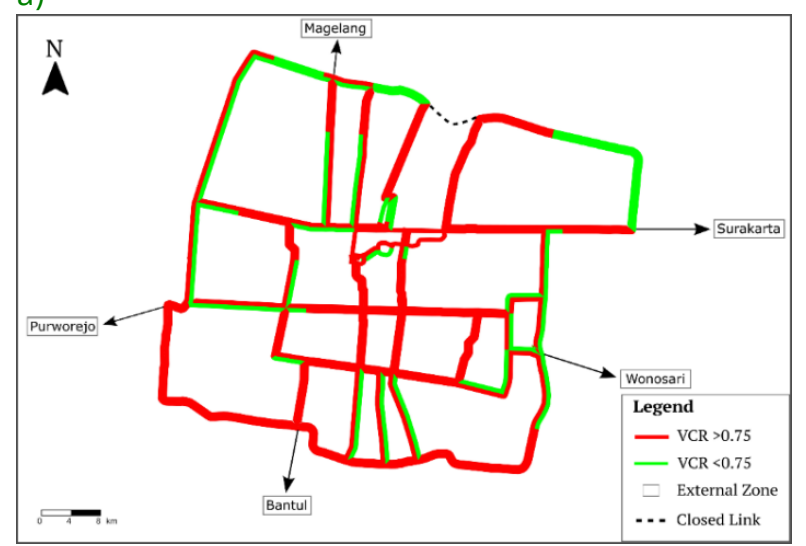

b)

Figure 4. Simulation result of road condition between with and without incident during peak hour: a) The Volume Capacity Ratio without road closure/incident, b) The Volume Capacity Ratio with road closure/incident

\subsection{Quantification of Vulnerability Index}

The vulnerability models in this study were developed based on four different quantification mechanisms, which had similar scoring variations
(1 to 4 ). The higher the vulnerability score, the worse the road performance impact. Therefore, the most critical road incident was identified by the highest vulnerability score. Based on Table 3, the four vulnerability models (M1, M2, M3, M4) showed that the worst impact occurred at a closure link of 47, i.e., Jalan Ring Road Utara Kentungan-Gejayan (Figure $4 \mathrm{~b}$ ). However, the subsequent order for the top 5 most vulnerable roads was different. The M3 and M4 models also provided a clear priority order from the best to the worst, although M1 and M2 produced indefinite orders, e.g., some roads with similar scores. Despite the simple quantification procedures on M1 and M2, the M3 and M4 models still offered more sensitive and accurate results through decimal scores. In addition, M1 and M2 did not show the priority order outside the top 5, compared to the M3 and M4 models.

Based on Table 3, all vulnerability components had a positive value except the vehicle kilometre travel This indicated that the road disturbance provided an opposite impact from the presumption. Although the incident worsened the other performance indicators $(V C R, v, V H T)$, it still offered certain benefits such as increased mobility performance (reduced VKT), due to shorter travel distance. Meanwhile, an argument stated that the benefit should be ignored due to the vulnerability focusing on negative impact or 
exposure. Furthermore, a shorter travel distance was found to be meaningless with a drastic increase in time, indicating that the total road user cost (RUC) is continuously integrated due to delays (longer travel times). Therefore, the negative scores were ignored and set as zero. In this case, there was no significant difference for the top 5 worst impacts. Also, the changing priority order was only identified at the lowest two impacts, such as 88 and 89 . This indicated that the choice to set the negative value at zero was optional in measuring the RCI, based on the insignificance of the impact.

Table 3. The most critical incidents based on vulnerability model alternatives

\begin{tabular}{|c|c|c|c|c|c|c|c|}
\hline \multicolumn{8}{|l|}{$\overline{\text { M1 }}$} \\
\hline \multicolumn{2}{|c|}{ Location } & \multicolumn{4}{|c|}{ Component } & \multirow{2}{*}{$\begin{array}{l}\text { RCI } \\
\text { score }\end{array}$} & \multirow{2}{*}{ Priority } \\
\hline Link & $\mathrm{F}^{*}$ & $\overline{V C R}$ & Speed & VHT & $V K T$ & & \\
\hline 47 & $\mathrm{AP}$ & 1 & 1 & 1 & 1 & 4 & 1 \\
\hline 52 & AP & 1 & 1 & 1 & 0 & 3 & 2 \\
\hline 69 & $\mathrm{AP}$ & 1 & 1 & 1 & 0 & 3 & 2 \\
\hline 83 & AP & 0 & 1 & 0 & 1 & 2 & 3 \\
\hline 70 & $\mathrm{AP}$ & 1 & 0 & 1 & 0 & 2 & 3 \\
\hline \multicolumn{8}{|l|}{ M2 } \\
\hline \multicolumn{2}{|c|}{ Location } & \multicolumn{4}{|c|}{ Component } & RCI & \multirow{2}{*}{ Priority } \\
\hline Link & $F^{*}$ & VCR & Speed & VHT & $V K T$ & score & \\
\hline 47 & $\mathrm{AP}$ & 1 & 1 & 1 & 1 & 4 & 1 \\
\hline 49 & $\mathrm{AP}$ & 0 & 0 & 1 & 1 & 2 & 2 \\
\hline 48 & $\mathrm{AP}$ & 0 & 0 & 1 & 1 & 2 & 2 \\
\hline 83 & $\mathrm{AP}$ & 0 & 1 & 0 & 1 & 2 & 2 \\
\hline 82 & AP & 0 & 0 & 1 & 1 & 2 & 2 \\
\hline \multicolumn{8}{|l|}{ M3 } \\
\hline \multicolumn{2}{|c|}{ Location } & \multicolumn{4}{|c|}{ Component } & RCI & \multirow{2}{*}{ Priority } \\
\hline Link & $\mathrm{F}^{*}$ & VCR & Speed & VHT & $V K T$ & score & \\
\hline 47 & $\mathrm{AP}$ & 1.00 & 1.00 & 0.98 & 1.00 & 3.98 & 1 \\
\hline 52 & AP & 0.96 & 0.94 & 1.00 & 0.55 & 3.45 & 2 \\
\hline 83 & AP & 0.82 & 0.90 & 0.74 & 0.92 & 3.38 & 3 \\
\hline 69 & AP & 0.94 & 0.91 & 0.99 & 0.27 & 3.11 & 4 \\
\hline 49 & AP & 0.84 & 0.89 & 0.59 & 0.61 & 2.94 & 5 \\
\hline$\vdots$ & $\vdots$ & $\vdots$ & $\vdots$ & $\vdots$ & $\vdots$ & $\vdots$ & $\vdots$ \\
\hline 42 & AP & 0.68 & 0.74 & 0.11 & -0.94 & 0.59 & 88 \\
\hline 43 & AP & 0.69 & 0.76 & 0.12 & -1.07 & 0.50 & 89 \\
\hline \multicolumn{8}{|l|}{ M4 } \\
\hline \multicolumn{2}{|c|}{ Location } & \multicolumn{4}{|c|}{ Component } & RCI & \multirow{2}{*}{ Priority } \\
\hline Link & $\mathrm{F}^{*}$ & $\overline{V C R}$ & Speed & VHT & $V K T$ & score & \\
\hline 47 & $\mathrm{AP}$ & 1.00 & 1.00 & 0.98 & 1.00 & 3.98 & 1 \\
\hline 83 & $\mathrm{AP}$ & 0.76 & 0.89 & 0.74 & 0.92 & 3.32 & 2 \\
\hline 52 & AP & 0.79 & 0.67 & 1.00 & 0.55 & 3.00 & 3 \\
\hline 49 & AP & 0.87 & 0.89 & 0.59 & 0.61 & 2.97 & 4 \\
\hline 69 & AP & 0.78 & 0.68 & 0.99 & 0.27 & 2.73 & 5 \\
\hline$\vdots$ & $\vdots$ & $\vdots$ & $\vdots$ & $\vdots$ & $\vdots$ & $\vdots$ & $\vdots$ \\
\hline 42 & $\mathrm{AP}$ & 0.72 & 0.52 & 0.11 & -0.94 & 0.40 & 88 \\
\hline 43 & AP & 0.76 & 0.52 & 0.12 & -1.07 & 0.33 & 89 \\
\hline
\end{tabular}

\section{DISCUSSION}

\subsection{Vulnerability Index}

The vulnerability model in this study combined a local (road section) and global (network) parameter into a single index. As a local parameter, VCR and travel speed described the service performance of a road section, while VHT and VKT defined the mobility efficiency of a systematic network. For behavioural knowledge, a relationship between vulnerability score and basic road features such as capacity and volume were explored (Figure 5).

Based on Figure 5, most of the data were scattered, as there was no strong relationship pattern between the road characteristics and vulnerability score. However, the most delicate pattern was identified on traffic volume, which had a positive relationship, therefore, representing the most significant parameter to briefly identify the critical location. This indicated that higher traffic volume led to more road network vulnerability with the occurrence of disruption. When a linear regression was applied, the highest relationship between traffic volume and vulnerability score was observed in the M3 and M4 models, at the determination coefficient (R-squared) values of 0.34 and 0.28 , respectively. Although M3 was the best model to show this relationship, the $\mathrm{R}$-squared value indicated that traffic volume only contributed $34 \%$ to the overall vulnerability score. This showed that the remaining contribution (66\%) was influenced by other parameters, including non-traffic-related factors such as road density and infrastructure conditions. Therefore, the RCI measurement using the M3 model was suitable for the general conditions, due to being the most sensitive parameter. Meanwhile, the M4 was considered when an official minimum standard/threshold for road service performance was available.

The RCI calculation indicated the similarities of the two most critical roads (link 47 and 52), compared to the existing performance indicator in Indonesia (VCR or VCR+speed). However, the remaining ranking orders were found to be different (Table 4). For instance, the result 


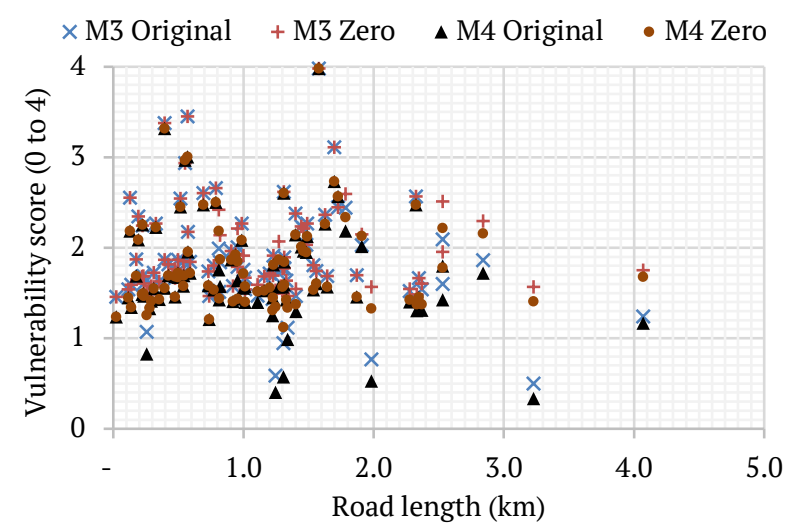

a)

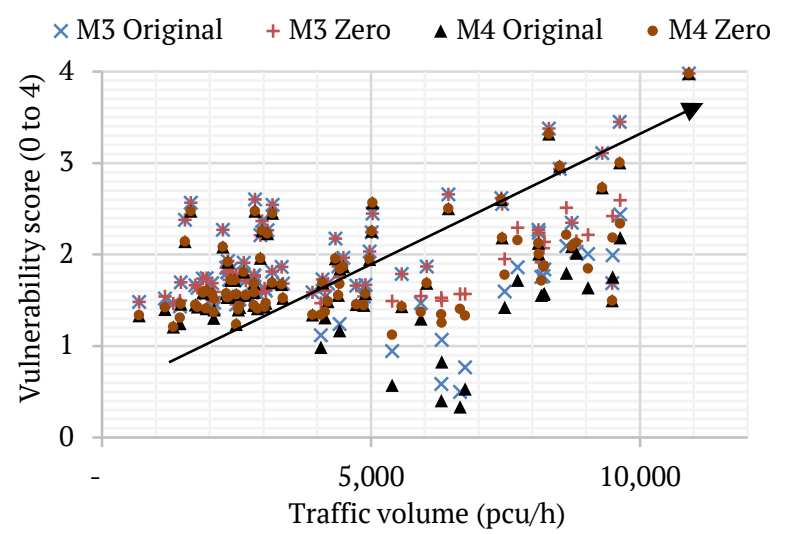

b)

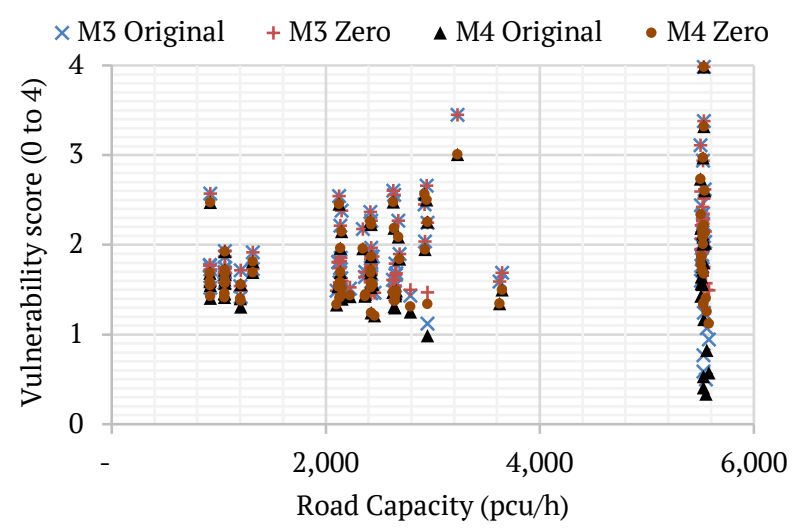

c)

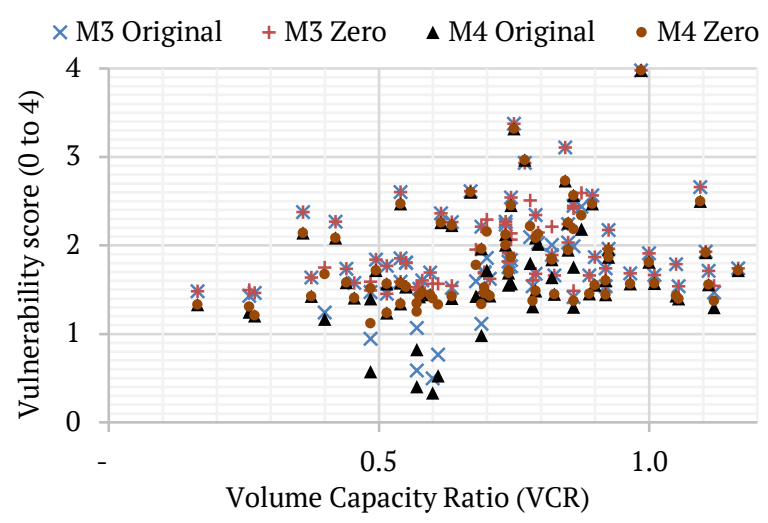

d)

Figure 5. Relationship between basic road characteristics with the vulnerability score (RCI): a) Road length, b) Traffic volume, c) Road capacity, d) Volume capacity ratio $(V C R)$. indicated that link 69 had a worse impact on local road performance than 83. Meanwhile, when the network performance was considered, the RCI model indicated that link 83 was more significant than 69. Based on this study, the vulnerability assessment generally encouraged road managers to spend maintenance/development budgets on the most critical network(s). Since the budget is limited, the prioritization mechanism for allocation was crucial. According to these considerations, the RCI application offered a more comprehensive approach than the existing ( $V C R$ or $V C R+$ Speed) indicator, to measure the criticality level of road(s) in an urban network. This RCI is specially developed based on urban road characteristics, as well as providing a more sensitive score result and combining both local and global network parameters. Therefore, this model offered a better approach that satisfied both the theoretical and practical aspects of this study.

Table 4. Top 10 most critical road

\begin{tabular}{lllllllllll}
\hline \multirow{2}{*}{ Indicator } & \multicolumn{10}{l}{ Priority order } \\
\cline { 2 - 10 } & 1 & 2 & 3 & 4 & 5 & 6 & 7 & 8 & 9 & 10 \\
\hline$V C R$ & 47 & 52 & 69 & 70 & 1 & 4 & 51 & 71 & 3 & 48 \\
Speed $(v)$ & 47 & 52 & 69 & 83 & 49 & 48 & 70 & 11 & 82 & 68 \\
$V C R+v$ & 47 & 52 & 69 & 70 & 4 & 49 & 48 & 51 & 71 & 1 \\
RCI-M3 & 47 & 52 & 83 & 69 & 49 & 57 & 48 & 11 & 56 & 23 \\
\hline
\end{tabular}

\subsection{Application of Vulnerability index}

The concept of vulnerability focuses on weakness and failure consequences of network degradation (Taylor et al., 2006). Based on this study, a sequential link(s) removal procedure to investigate the most vulnerable road section(s) has successfully been confirmed. According to the study of Balijepalli and Oppong (2014), NVI was applied as a vulnerability assessment to the road network due to flooding. Furthermore, El-Rashidy and Grant-Muller (2014) demonstrated the use of six assessment variables, such as $V C R$, volume, travel time, road capacity and length, as well as the shortest route, for measuring vulnerability in the urban network. The study of Taylor (2017) also used $V H T$ for calculating the network trip robustness index (NTRI), a vulnerability parameter used in regional road structures. These previous studies indicated that vulnerability 
should be measured using various indicators. However, the selection of vulnerability index should consider the measurement objectives and theoretical frameworks. For example, accessibility indicators such as the NTRI or Hansen index should be more effective when being applied for regional road networks (Susilawati and Taylor, 2008). The implementation of these indexes in an urban network is likely to be biased, based on sharing different characteristics (Sugishita and Asakura, 2021).

According to the theoretical concept, vulnerability analysis is the first stage to maintain road network connectivity and performance. Based on the knowledge of the most vulnerable road locations and their consequences, authorities should prioritize maintenance and development strategies to protect and improve alternative routes for mitigating the traffic detour impacts. Also, road managers can practically use the vulnerability assessment to raise public awareness, and support the feasibility of network development. Furthermore, several management strategies should be proposed, including an infrastructure-based approach such as road density increase. This is because a higher road density is known to offer a more resilient network as alternative routes options when a particular link is disrupted. However, the strategy to build a new road(s) should not always be the best solution, because of the expensive cost and limited land for development. Using suitable traffic management systems, the optimization of the exiting road asset is found to be more favoured.

In terms of transportation management, the information system played a crucial role in mitigating the impact of road disruption or closure. Although access is disrupted, road users still need to reach their destination as fast as possible. When these users are well-informed on the occurrence of incidents, immediate reactions are actively carried out by identifying and selecting the best alternative route option. This was in line with the equilibrium traffic assignment procedure applied in the PTV Visum model. However, the impact dramatically worsens when the information is not accurately delivered. In this case, the implementation of intelligent transport systems in urban road networks, such as vehicle message signs (VMS) and route guidance systems, should be prioritized to assist the police/traffic officers in normalizing and diverting vehicle flow from the disruptions.

The concept of road maintenance is generally responsive in developing countries, where waiting until a section is damaged near the tolerance threshold is often observed. In this condition, roadwork is immediately carried out without considering the sustainability of investment value from road assets. This is because a road network is always technically wanted in a prime condition. However, a road manager only realistically optimizes a limited budget far from the required cost. Therefore, these managers should make efforts to handle investments, and focus on more significant impact roads. To solve this problem, the concept of vulnerability should be used to examine potential impacts, and also identify the most critical road(s) with the worst consequences on the overall network performance. By analyzing this vulnerability, the road manager should prioritize roadworks based on the criticality index, and also conduct preventive measures to mitigate risk under a constrained budget.

\section{CONCLUSION}

This study developed an alternative vulnerability model (RCI) and indicated the identification of the most critical location of road incidents in an urban area. Due to unforeseen incidents, the vulnerability of road network performance varied based on traffic volume and pattern, as well as road density and configuration. This assessment encouraged road managers to spend maintenance/development budgets on the most critical network(s). The vulnerability assessment was also important due to the massive impact of disturbance on the critical $\operatorname{road}(s)$, which triggered a systemic chain effect on the overall network performances, including substantial losses on social-economic activity. Since the management budget was always limited, the 
prioritization mechanism for allocating the budget was often crucial. By analyzing this vulnerability, the road manager should prioritize roadworks based on the criticality index, and conduct preventive measures to mitigate risk under a constrained budget. Based on this study, the results emphasized that vulnerability mitigation in urban road networks was an issue of prevention and preparedness for quick restoration, compared to providing expensive infrastructure investment such as building new $\operatorname{road}(\mathrm{s})$. A link closure is not likely to be crucial in vulnerability analysis when it has an alternative route to mitigate the impact. Although the best response to optimize road network performance was through vulnerability analysis, the risk and road asset investment value through socioeconomic analysis should also be considered. Despite the test of the overall approaches in this study, the developed vulnerability model can be adopted and applied to other areas or countries. For further studies, the transport mode, destination choice, budget allocation, and socioeconomic impact can be considered in assessing vulnerability levels, as well as developing road management standards and strategies.

\section{DISCLAIMER}

The authors declare no conflict of interest.

\section{AVAILABILITY OF DATA AND MATERIALS}

All data are available from the author.

\section{AUTHOR CONTRIBUTION STATEMENTS}

Mukhammad R. F. A. developed the concept, methodology and performed the analytical results. Raihan P. I. carried out the PTV Visum simulation. Both authors took a substantial contribution in discussing the result and writing the manuscript.

\section{ACKNOWLEDGMENTS}

The authors are grateful to the Civil and Environmental Engineering Department, as well as the Computation Laboratory of Master Program in Transport System and Engineering, Faculty of Engineering, Universitas Gadjah Mada
(DTSL FT UGM), for financially supporting this study and facilitating the PTV Visum software, respectively.

\section{REFERENCES}

Amrozi, M.R.F. and Evdorides, H.T. 2019. Economic Optimisation of Road Network Accessibility. Bituminous Mixtures and Pavements VII. CRC Press. pp. 499-506.

Auerbach, M., Hammoum, F., Huber, F., Hunyadi, D., Krieger, B., Marchese, A., Maruntu, C., Murphy, H. and Reeves, S. 2016. Transport Strategies for Climate Change Mitigation and Adaptation. France: The World Road Association (PIARC).

Balijepalli, C. and Oppong, O. 2014. Measuring vulnerability of road network considering the extent of serviceability of critical road links in urban areas. Journal of Transport Geography 39 145-155.

Berdica, K., 2002. An Introduction to Road Vulnerability: What Has Been Done, is Done and Should be Done. Transport Policy ,9(2), pp. 117127.

BPS-statistics, 2021. Yogyakarta Municipality in Figures 2021. Yogyakarta: BPS-Statistic of Yogyakarta Municipality.

BSN, 2004. RSNI T-14-2004: Urban Road Geometry. Jakarta: National Standardization Agency (BSN).

El-Rashidy, R.A. and Grant-Muller, S.M., 2014. An Assessment Method for Highway Network Vulnerability. Journal of Transport Geography, 34, pp. 34-43.

Fitrada, A.G., Munawar, A., and Dewanti, 2019. Investigating the Impact of Airport Relocation on the Transport Network in Special Region of Yogyakarta, Indonesia. Journal of The Civil Engineering Forum, 5 (2), pp. 93-104.

IHCM 1997. Indonesia Highway Capacity Manual (MKJI). Jakarta: Ministry of Public Work Republic Indonesia. 
Jenelius, E. and Mattsson, L.-G., 2015. Road Network Vulnerability Analysis: Conceptualization, Implementation and Application. Computers, Environment and Urban Systems, 49, pp. 136-147.

Karlaftis, M. and Kepaptsoglou, K., 2012. Performance Measurement in The Road Sector: A Cross-Country Review of Experience, International Transport Forum Discussion Paper.

Litman, T. 2016. Accessibility for Transportation Planning: Measuring People's Ability to Reach Desired Goods and Activities. Victoria Transport Policy Institute.

Mahpudin, M., Kelihu, A., and Sarmiasih, M. 2020. The Rise of Student Social Movement: Case Study of \#GejayanCalling Movement in Yogyakarta. International Journal of Demos, 2(1), pp.21-42.

Ministry of Transport, 2006. Kepmenhub KM 14/2006 concerning Road Traffic Management and Engineering. Jakarta : Ministry of Transport.

Ministry of Transport, 2015. Permenhub PM 96/2015 concerning Guidelines for the Implementation of Traffic Management and Engineering Activities. Jakarta: Ministry of Transport.

Nagurney, A. and Qiang, Q. 2008. A Network Efficiency Measure with Application to Critical Infrastructure Networks. Journal of Global Optimization, 40(1-3), pp. 261-275.

Nardo, M., Saisana, M., Saltelli, A., Tarantola, S., Hoffmann, A., and Giovannini, E., 2008. Handbook on Constructing Composite Indicators: Methodology and User Guide. Ispra: OECD publishing.

OECD 2001. Performance Indicators for the Road Sector. Paris: Organisation for Economic CoOperation and Development (OECD).

Oliveira, E.L.D., Portugal, L.D.S., and Junior, W.P., 2016. Indicators of Reliability and Vulnerability: Similarities and Differences in Ranking Links of a Complex Road System.
Transportation Research Part A: Policy and Practice, 88, pp. 195-208.

PTV, A. 2021. PTV Visum 2021 Manual. Karlsruhe: PTV Group.

Rupi, F., Bernardi, S., Rossi, G., and Danesi, A., 2015. The Evaluation of Road Network Vulnerability in Mountainous Areas: A Case Study. Networks and Spatial Economics, 15(2), pp. 397-411.

Scott, D.M., Novak, D.C., Aultman-Hall, L., and Guo, F., 2006. Network Robustness Index: A new method for identifying critical links and evaluating the performance of transportation networks. Journal of Transport Geography 14(3) 215-227.

Stanton-Geddes, Z. and Vun, Y.J., 2019. Strengthening the Disaster Resilience of Indonesian Cities, Washington DC.: World Bank.

Sudibyo, T., Mahardi, P., and Prasetyo, T., 2017. Comparison of Road Service Level Assessment based on PM 96/2015 and KM 14/2006. Prosiding Konferensi Nasional Teknik Sipil, 11, pp. 183-188.

Sugishita, K. and Asakura, Y., 2021. Vulnerability Studies in the Fields of Transportation and Complex Networks: A Citation Network Analysis. Public Transport, 13(1), pp. 1-34.

Sullivan, J.L., Novak, D.C., Aultman-Hall, L., and Scott, D.M., 2010. Identifying Critical Road Segments and Measuring System-Wide Robustness in transportation Networks with isolating links: A Link-Based Capacity-Reduction Approach. Transportation Research Part A: Policy and Practice, 44(5), pp. 323-336.

Susilawati and Taylor, M., 2008. An Accessibility Approach in Assessing Regional Road Network Vulnerability. Gold Coast: 31st Australasian Transport Research Forum.

Tamin, O.Z., 2000. Transportation Planning and Modeling: Bandung: ITB Publisher.

Taylor, M., 2017. Vulnerability Analysis for Transportation Networks, Amsterdam: Elsevier. 
Taylor, M.A.P., Sekhar, S.V.C., and D'Este, G.M., 2006. Application of Accessibility Based Methods for Vulnerability Analysis of Strategic Road Networks. Networks and Spatial Economics, 6(3-4), pp. 267-291.
Taylor, M.A.P. and Susilawati 2012. Remoteness and Accessibility in the Vulnerability Analysis of Regional Road Networks. Transportation Research Part A: Policy and Practice, 46(5), pp. 761-771. 
[This page is intentionally left blank] 